\title{
Pemanfaatan Batubara Kalori Rendah Pada PLTU untuk Menurunkan Biaya Bahan Bakar Produksi
}

\author{
Suriyan Arif Wibowo, Jaka Windarta \\ Magister Energi, Sekolah Pascasarjana, Universitas Diponegoro;; \\ Email : suriyan@students.undip.ac.id (S.A.W), jakawindarta@lecturer.undip.ac.id (J.W);
}

\begin{abstract}
Abstrak : Tingginya jumlah sumber daya dan cadangan batubara kalori rendah, perlu untuk ditingkatkan pemanfaatannya. Penyediaan energi sampai dengan tahun 2050 diperkirakan tetap didominasi oleh energi fosil. Energi fosil yang tumbuh paling pesat adalah batubara karena sektor pembangkit listrik didominasi oleh PLTU batubara. Sebagai salah satu upaya untuk memanfaatkan batubara nilai kalori rendah yang mempunyai harga energi yang relatif lebih murah, maka dapat dilakukan alternatif pemanfaatan batubara tersebut dengan metode coal blending, coal switching, ataupun coal drying pada PLTU. Coal blending merupakan cara terbaik untuk mengatasi masalah ketersediaan batubara dan ketergantungan terhadap satu sumber pemasok batubara untuk PLTU di Indonesia. Dengan mengganti batubara menjadi kalori yang lebih rendah (coal switching) memang akan menaikkan jumlah konsumsi batu bara, namun karena harganya lebih murah, maka masih didapat penghematan secara finansial. Coal drying dapat menjadi salah satu alternatif untuk memperbaiki kualitas batubara yang mempunyai kandungan moisture tinggi, sehingga batubara tersebut dapat digunakan untuk bahan bakar PLTU eksisting.
\end{abstract}

Kata Kunci : PLTU, boiler, coal blending, coal switching, coal drying

\section{Pendahuluan}

Batubara terdiri dari 1.029 lokasi yang tersebar di pulau Sumatera, pulau Jawa bagian barat, pulau Kalimantan, pulau Sulawesi bagian selatan, dan pulau Papua. Hasil perhitungan keseluruhan menunjukkan bahwa sumber daya batubara Indonesia sampai dengan Desember 2017 adalah sebesar $125.177,59$ juta ton batubara, sedangkan cadangan batubara sebesar 24.239,96 juta ton. Apabila dibandingkan dengan neraca Desember 2016, terdapat penurunan sumber daya batubara sebesar 2.885,05 juta ton, sedangkan cadangan batubara pada tahun 2016 mengalami penurunan sebanyak $4.217,33$ juta ton. Penurunan angka cadangan batubara sangat terkait dengan kondisi ekonomi global yang dipicu oleh melemahnya harga minyak bumi. Harga batubara secara tidak langsung ikut turun seiring turunnya harga minyak bumi. Hal ini mempengaruhi perhitungan cadangan batubara yang sangat tergantung pada berbagai faktor penentu, diantaranya harga jual batubara (ESDM, 2019). Sesuai dengan SNI 5015 tahun 2011, sumber daya hipotetik ditiadakan karena merupakan tanggung jawab pemerintah untuk melaksanakan penyelidikan pendahuluan yang menghasilkan sumber daya hipotetik. Jadi nilai sumber daya dan cadangan yang ditampilkan adalah nilai yang dihasilkan oleh 
perusahaan pemegang izin Pemegang Karya Pengusahaan Pertambangan Batubara (PKP2B) dan Izin Usaha Pertambangan (IUP).

Tabel 1.

Sumber daya dan cadangan batubara Indonesia

\begin{tabular}{cccccccc}
\hline \multirow{2}{*}{ Kualitas } & \multicolumn{3}{c}{ Sumber Daya (Juta Ton) } & \multicolumn{3}{c}{ Cadangan (Juta Ton) } \\
\cline { 2 - 7 } & Tereka & Tertunjuk & Terukur & Total & Terkira & Terbukti & Total \\
\hline $\begin{array}{c}\text { Kalori Rendah } \\
(<5100 \mathrm{kcal} / \mathrm{kg})\end{array}$ & $1,263.95$ & $5,913.98$ & $6,420.26$ & $3,598.19$ & $7,108.27$ & $7,121.47$ & $14,229.74$ \\
$\begin{array}{c}\text { Kalori Sedang } \\
(5100-6100 \\
\quad \mathrm{kcal} / \mathrm{kg})\end{array}$ & $27,436.16$ & $19,822.35$ & $20,357.92$ & $67,616.43$ & $3,570.70$ & $6,841.66$ & $10,412.36$ \\
$\begin{array}{c}\text { Kalori Tinggi } \\
(6100-7100\end{array}$ & $3,967.88$ & $2,480.65$ & $2,804.63$ & $9,253.15$ & 541.60 & $2,769.20$ & $3,310.80$ \\
$\quad \mathrm{kcal} / \mathrm{kg})$ & & & & & & & \\
$\begin{array}{c}\text { Kalori Sangat } \\
\text { Tinggi }\end{array}$ & $1,726.74$ & 735.33 & 600.00 & $3,062.07$ & 264.19 & 240.21 & 504.40 \\
$(>7100 \mathrm{kcal} / \mathrm{kg})$ & & & & & & & \\
\hline Jumlah & $44,394.73$ & $38,952.31$ & $40,182.81$ & $123,529.84$ & $11,484.76$ & $16,972.54$ & $28,457.30$ \\
\hline
\end{tabular}

Data tersebut dalam adb (ash dried basis). Pembagian kualitas batubara berdasarkan kelas nilai kalori tersebut sesuai dengan Keputusan Presiden Nomor 13 Tahun 2000 yang diperbarui dengan Peraturan Pemerintah Nomor 45 Tahun 2003 tentang Tarif Atas Jenis Penerimaan Negara Bukan Pajak yang berlaku pada Departemen Energi dan Sumber Daya Mineral. Angka calorific value yang sering dipakai oleh PLN dalam rangka desain PLTU adalah menggunakan standar GAR (gross as received). Perbedaan antara adb dan GAR dapat dihitung sesuai dengan nilai TM (total moisture) (Zhu, 2010).

Walaupun cadangan batubara Indonesia tidak terlalu besar, namun tingkat produksi batubara sangat tinggi, yaitu mencapai 461 juta ton pada tahun 2017. Sebagian besar dari produksi batubara terse but diekspor ke China, India, Jepang, Korea Selatan dan Taiwan dan negara lain. Dengan asumsi tingkat produksi batubara setelah tahun 2019 tetap sebesar 400 juta ton dan tidak ada penambahan cadangan baru, maka seluruh cadangan batubara Indonesia sebesar 24.239,96 juta ton diatas diperkirakan akan habis dalam waktu sekitar 61 tahun (tahun 2079). Untuk menjamin pasokan kebutuhan domestik yang terus meningkat, pemerintah telah menerapkan kebijakan Domestic Market Obligation (DMO) sesuai Peraturan Menteri ESDM No. 34 tahun 2009 tentang Pengutamaan Pemasokan Kebutuhan Mineral dan Batubara untuk Kepentingan Dalam Negeri yang mewajibkan badan usaha pertambangan mineral dan batubara untuk mengutamakan pasokan mineral dan batubara untuk kepentingan dalam negeri. Pengguna batubara dalam negeri terbesar adalah pembangkit listrik sebesar $81 \%$, sedangkan sebagian kecil untuk industri semen, tekstil, pupuk, pulp dan metalurgi yang lokasi penggunanya paling banyak terdapat di Jawa. Harga batubara di pasar internasional yang cenderung naik pada akhir 2016 dan stabil tinggi di tahun 2017 akibat kenaikan demand batubara global telah membuat biaya pokok penyediaan energi primer terutama batubara menjadi lebih tinggi (PT. PLN (Persero), 2019).

Sebagian besar PLTU yang dibangun di Jawa sejak awal tahun 1980 sampai pertengahan 2010 menggunakan batubara kalori sedang. Sedangkan tingginya jumlah sumber daya dan cadangan 
batubara kalori rendah, perlu untuk ditingkatkan pemanfaatannya. Sebagai salah satu upaya untuk memanfaatkan batubara nilai kalori rendah yang mempunyai harga energi yang relatif lebih murah, maka dapat dilakukan alternatif pemanfaatan batubara tersebut dengan metode coal blending, coal switching, ataupun coal drying pada PLTU.

\section{Prinsip kerja PLTU}

PLTU adalah sebuah sistem yang berfungsi untuk mengkonversi energi kimia dari bahan bakar menjadi energi listrik. Peralatan utama dari pembangkit listrik tenaga uap (PLTU) berbahan bakar batubara adalah sistem coal handling, boiler, turbin, generator dan sistem pendingin. Coal handling system berfungsi untuk menyalurkan batubara dari kapal pengangkut batubara menuju ke boiler. Boiler berfungsi untuk merubah energi kimia menjadi energi panas, panas yang dihasilkan boiler dimanfaatkan untuk memanaskan air dalam pipa boile menjadi uap superheat dengan temperature dan tekanan tinggi. Uap tersebut kemudian dipakai untuk memutar turbin yang dikopel langsung dengan generator sinkron untuk menghasilkan energi listrik. Setelah melewati turbin uap, uap yang bertekanan dan bertemperatur tinggi yang berasal dari boiler tadi menjadi uap bertekanan dan bertemperatur rendah, kemudian uap ini masuk ke kondensor dan panas uap ini kemudian diserap oleh kondensor sehingga uap tersebut berubah menjadi air yang kemudian dipompakan kembali menuju boiler (Tirumala Srinivas, 2017). Proses konversi energi pada PLTU dapat dilihat pada gambar 1. Boiler adalah bejana tertutup sebagai penghasil panas pembakaran yang dipindahkan ke dalam air hingga menjadi air atau uap panas. Panas dipindahkan dari satu benda ke benda lain melalui radiasi, yaitu perpindahan panas dari benda panas ke benda dingin tanpa media pembawa, konveksi adalah perpindahan panas dengan media pembawa, seperti udara atau air, dan konduksi adalah perpindahan panas dengan kontak fisik yang sebenarnya, molekul ke molekul (Aravind et al., 2020).

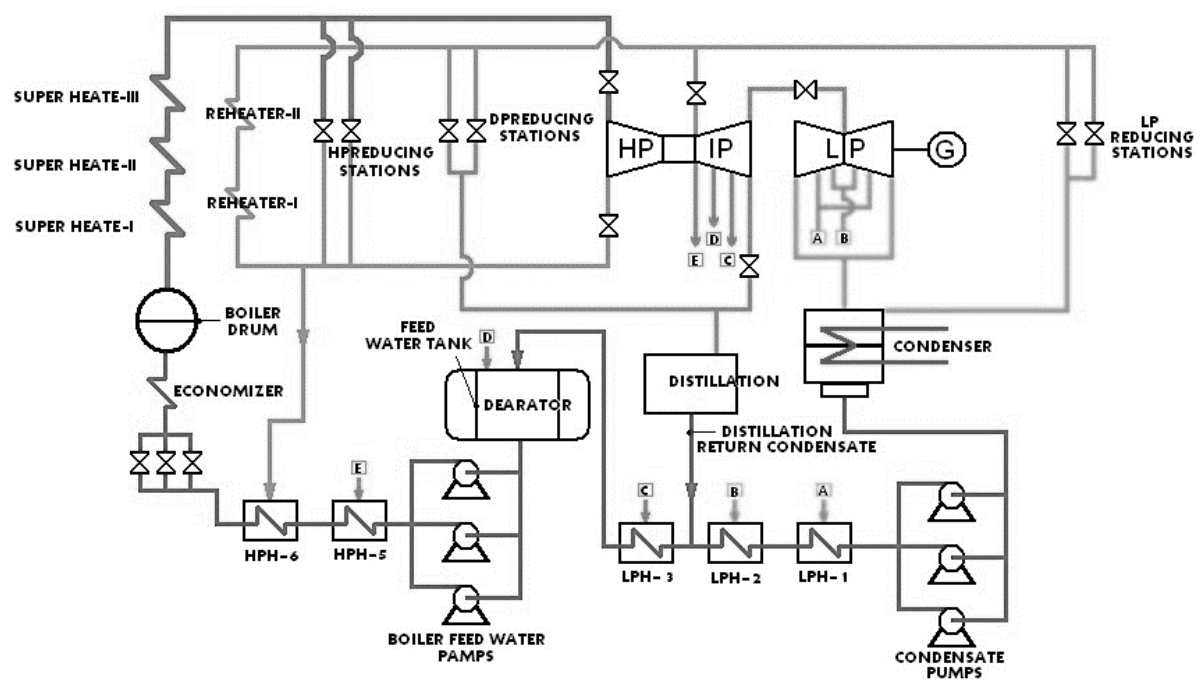

Gambar 1. Diagram proses PLTU batubara

Efisiensi adalah salah satu parameter yang digunakan untuk mengevaluasi kinerja suatu pembangkit thermal. Nilai efisiensi untuk jenis pembangkit PLTU subcritical pada umumnya sekitar $35 \%$, jika nilai efisiensi dibawah 35\% maka pembangkit dapat kurang baik untuk beroprasi (Anang Nungky Ristyanto, Joko Windarto, 2012). 


\section{Coal Bending}

Coal blending adalah salah satu cara untuk menyesuaikan parameter kualitas batubara yang dijual agar sesuai dengan kriteria yang diharapkan dengan melakukan pencampuran dua atau lebih jenis batubara yang berbeda kualitasnya (Amsya \& Pelita, 2019). Pencampuran untuk bahan bakar padat melibatkan produksi campuran yang cukup homogen dari dua atau lebih padatan untuk dibakar dalam boiler. Padatan ini dapat berupa batubara dengan tingkatan yang sama atau serupa, batubara dengan tingkatan yang berbeda, batubara dengan bahan bakar biomassa seperti kayu, sisa kayu, tanaman herba, dan sisa tanaman; kotoran dari hewan, dan residu industri dari pengolahan biomassa. Campuran juga dapat mencakup batubara dan berbagai bahan dan residu industri, termasuk kokas minyak bumi dari satu jenis atau jenis lainnya, asam karboksilat produk sampingan, limbah batubara seperti batang atau gob, bahan bakar yang berasal dari limbah padat kota (misalnya, bahan bakar yang berasal dari sampah, kertas bekas, limbah plastik), bahan bakar yang berasal dari ban, limbah berbahaya pilihan, dan banyak lagi.

Pada PLTU umumnya pencampuran terjadi di stockpile atau boiler. Namun, hal ini juga dapat terjadi di fasilitas manajemen bahan bakar di luar lokasi dengan campuran dikirim ke pembangkit listrik atau industri. Hal ini dapat terjadi sebagai bagian dari proses penanganan bahan bakar: dalam sistem umpan yang membawa bahan bakar (conveyor) ke burner atau sistem pemulihan dan produksi energi lainnya (misalnya sistem pembakaran atau gasifikasi). Hal ini dapat terjadi pada peralatan produksi energi (contohnya pulverized boiler) tergantung pada desain sistem. Dalam hal ini pulverizer tertentu dipasang untuk satu jenis batubara, dan pulverizer yang lain disiapkan untuk batubara hasil coal blending (Tillman, 2012).

Secara matematis, mencampur dua jenis batubara relatif mudah, tetapi untuk tiga atau lebih jenis batubara akan menjadi lebih kompleks, karena terdapat lebih banyak parameter dan kemungkinan kombinasi blending. Oleh karena itu, software komputer yang sekarang banyak terdapat di pasaran dapat digunakan. Software tersebut dikembangkan menggunakan persamaan linier untuk parameter kualitas batubara yang bersifat aditif, terutama nilai kalor, kadar abu dan kadar sulfur. Rumus linier sederhana untuk blending batubara yang menggunakan parameter aditif adalah sebagai berikut:

$$
\mathrm{K}_{\mathrm{C}}=\frac{\mathrm{K}_{1} \mathrm{X}_{1}+\mathrm{K}_{2} \mathrm{X}_{2}+\ldots+\mathrm{K}_{\mathrm{n}} \mathrm{X}_{\mathrm{n}}}{\mathrm{X}_{1}+\mathrm{X}_{2}+\ldots+\mathrm{X}_{\mathrm{n}}}
$$

Dimana,

$\begin{array}{ll}\mathrm{K}_{\mathrm{C}} & =\text { kualitas hasil blending } \\ \mathrm{K}_{1} & =\text { kualitas batubara satu } \\ \mathrm{K}_{2} & =\text { kualitas batubara dua } \\ \mathrm{K}_{\mathrm{n}} & =\text { kualitas batubara } \mathrm{n} \\ \mathrm{X}_{1} & =\text { kuantitas batubara satu } \\ \mathrm{X}_{2} & =\text { kuantitas batubara dua } \\ \mathrm{X}_{\mathrm{n}} & \text { = kuantitas batubara } \mathrm{n}\end{array}$

Contoh proximate analysis hasil batubara campuran antara batubara A dengan komposisi $30 \%$ dan batubara B dengan komposisi 70\% dapat dilihat pada tabel 2 . 
Tabel 2.

Hasil coal blending dengan dua jenis batubara

\begin{tabular}{ccccc}
\hline Keterangan & Satuan & Batubara A & Batubara B & Hasil batubara campuran \\
\hline GCV & $\mathrm{kCal} / \mathrm{kg}$ & $4,583.33$ & $3,699.36$ & $3,964.55$ \\
Fixed Carbon & $\%$ & 36.21 & 29.26 & 31.34 \\
Total Moisture & $\%$ & 23.00 & 34.00 & 30.70 \\
Ash Content & $\%$ & 5.96 & 5.04 & 5.32 \\
Volatile Matter & $\%$ & 34.83 & 31.70 & 32.64 \\
\hline Komposisi campuran & $\%$ & 30.00 & 70.00 & \\
\hline
\end{tabular}

Coal blending merupakan cara terbaik untuk mengatasi masalah ketersediaan batubara dan ketergantungan terhadap satu sumber pemasok batubara untuk PLTU di Indonesia. Untuk mengatasi masalah pasokan batubara pada sebuah PLTU, coal blending dapat dilakukan antara batubara kalori rendah dan batubara kalori sedang sesuai dengan spesifikasi parameter kualitas batubara, terutama nilai kalor, kandungan abu dan sulfur. Batubara kalori sedang umumnya mempunyai Hardgrove Grindability Index (HGI) rendah atau sulit digerus dan parameter ini perlu diperhatikan karena cenderung tidak bersifat aditif sehingga hasil blending dengan batubara peringkat rendah tidak dapat diprediksi menggunakan persamaan linier. Data komposisi abu dan titik leleh abu batubara kalori sedang perlu dilengkapi agar dapat digunakan untuk mengevaluasi kemungkinan pembentukan slagging dan fouling dalam pembakaran batubara hasiI blending. Pengujian pengerusan dan pembakaran dalam skala yang mendekati kondisi nyata di lapangan perlu di lakukan untuk mengevaluasi batubara hasil blending (Suprapto, 2009).

\section{Coal Switching}

Coal switching adalah sebuah program merubah nilai kalori batubara yang digunakan untuk proses pembakaran boiler pada PLTU dari nilai desain boiler menjadi nilai kalori yang lebih rendah. Dengan mengganti batubara menjadi kalori yang lebih rendah memang akan menaikkan jumlah konsumsi batu bara, namun karena harganya lebih murah, maka masih didapat penghematan secara finansial (Mills, 2011).

Penggunaan kualitas batubara yang lebih rendah dari desain boiler tentunya akan menimbulkan potensi gangguan dalam operasional pembangkit sebagai berikut:

- Masalah Penanganan dan penyimpanan batubara dapat berubah.

- Batubara jenis lignit dapat memiliki masalah debu dan pembakaran spontan.

- Lebih banyak batubara harus dikelola jika nilai kalori batubara baru lebih rendah.

- Aliran batu bara dapat dipengaruhi oleh fineness, atau moisture, atau bahkan kandungan tanah liat.

- Kecepatan coal feeder dapat berubah tergantung pada kalori batubara dan efisiensi boiler.

- Efisiensi Boiler dan NPHR dapat dipengaruhi oleh perubahan kualitas batubara dan operasional.

- Kapasitas pulverizer dapat berubah. Perlu diperhatikan bahwa aliran batubara yang lebih tinggi cenderung meningkatkan ukuran partikel yang berdampak pada pembakaran, unburnt carbon, Nox, slagging, fouling, dan peningkatan Furnace Exit Gas Temperature (FEGT). 
- Risiko pembentukan slagging dan fouling dapat meningkat, sehingga memerlukan pengoperasian soot blower lebih sering.

- Karena jumlah abu yang terbentuk lebih banyak, maka memerlukan tempat penampungan abu yang lebih besar (Tanetsakunvatana \& Kuprianov, 2007).

\section{Coal Drying}

Teknologi pengeringan telah dikembangkan sejak tahun 1920-an. Pada tahun tersebut di Austria dikembangkan proses Fleissner untuk menurunkan kandungan air batubara peringkat rendah menggunakan media dan energi panas dari superheated steam. Saat ini telah banyak teknologi pengeringan batubara dikembangkan dan berdasarkan fasa air yang keluar dari batubara saat proses, teknologi pengeringan batubara dapat dikelompokkan menjadi teknologi evaporative dan nonevaporative. Pada teknologi evaporative, air dikeluarkan dari dalam batubara dalam fasa gas sedangkan pada teknologi non-evaporative karena penggunaan tekanan tinggi pada saat proses maka air keluar dari batubara dalam bentuk fasa cair. Sebagian besar teknologi pengeringan batubara adalah masuk ke dalam jenis teknologi evaporative seperti contoh teknologi UBC (upgraded brown coal), BCB (binderless coal briquetting), CUB (Coal Upgraded Briquettes) dan lain-lain. Teknologi yang termasuk ke dalam jenis non-evaporative adalah technology hydrothermal seperti CHTD. Alat yang digunakan untuk pengeringan batubara juga bermacam-macam seperti pengering putar (rotary dryer), flash dryer, fluidized bed dryer, slurry evaporator, autoclave dan hydraulic press (Sudirman, 2012).

\subsection{Rotary Dryer}

Pada industri, rotary dryer digunakan untuk mengeringkan batubara. Umumnya pengering ini beroperasi dalam mode cocurrent untuk menghindari kemungkinan batubara terbakar sendiri. Media pengering adalah udara panas atau gas hasil pembakaran yang berasal dari hasil pembakaran gas alam atau batubara. Sebuah pengering putar tipikal ditunjukkan secara skematis pada gambar 2 . Komponen utama pengering ini adalah shell baja dilapisi dengan lapisan tahan api dan dipasang pada roller dengan menggunakan bandages yang terletak di shell. Shell diputar menggunakan roda gigi. Shell dipasang miring dengan kemiringan 20 hingga 50 ke arah horizontal. Di dalam shell, ada pengangkat yang diikat ke permukaan bagian dalam drum. Selama operasi, pengangkat ini mengangkat butiran batubara dan menghujani batubara secara bertahap di dalam shell dengan aliran gas pemanas yang mengalir.

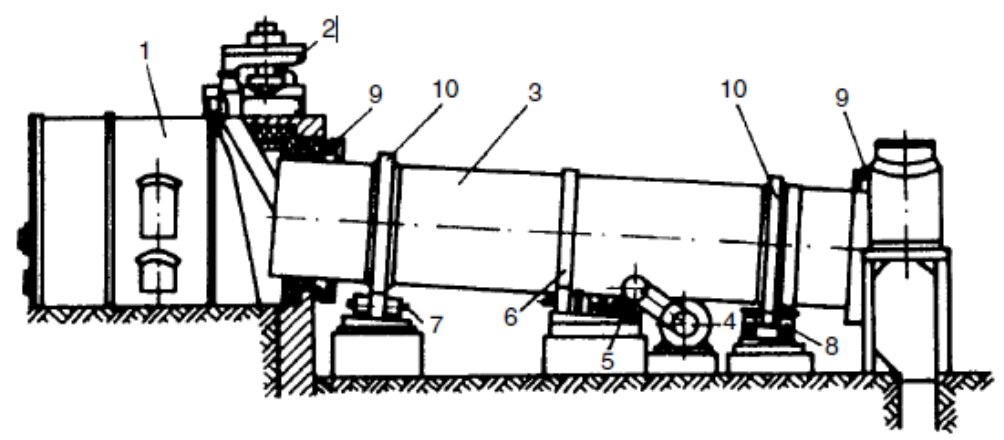

Gambar 2. Rotary Dryer 
Kerugian akhir batubara tidak melebihi 0,5 sampai 1,5\%, tergantung pada jenis peralatan yang digunakan untuk membersihkan pembakaran. Konsumsi panas dalam pengering tersebut berjumlah sekitar $3700 \mathrm{~kJ} / \mathrm{kg} \mathrm{H} \mathrm{H}_{2} \mathrm{O}$. Waktu pengeringan sekitar 15 hingga 40 menit pada fraksi penahanan 0,15 hingga 0,25. Kecepatan gas di outlet pengering tidak boleh lebih dari 2 hingga $3 \mathrm{~m} /$ detik untuk pengeringan batubara halus yang berasal dari pencucian dan tidak lebih dari 0,5 hingga $1 \mathrm{~m} /$ detik untuk konsentrat pasca pengapungan untuk menghindari terbawa batubara yang berlebihan (Pikon' \& Mujumdar, 2006).

\subsection{Rotary Tube Dryer}

Rotary tube dryer adalah salah satu perwakilan paling khas dari pengering pemanas tidak langsung. Ada dua cara utama untuk meningkatkan kemampuan pengeringan. Salah satunya adalah menjaga pergerakan relatif antara tabung pemanas dan partikel material. Rotary tube dryer digunakan secara luas untuk pengeringan batubara di pabrik briket batubara lignit dan PLTU yang menggunakan batubara dengan nilai kalori rendah. Pengering ini adalah pengering tidak langsung yang dihasilkan oleh uap jenuh pada tekanan 0,15 sampai 0,55 MPa. Pengering ini terdiri dari sloping drum, di mana dinding berlubang memiliki seamless tubes yang diikat pada diameter sekitar 102 hingga $108 \mathrm{~mm}$. Shell pengering menggulung pada cincin khusus dan roller dan digerakkan oleh daya yang disalurkan melalui roda gigi. Uap pemanas masuk ke drum melalui pin. Sebagian besar batubara dengan moisture tinggi diumpankan ke dalam tabung pemanas. Sebagai akibat dari kemiringan dan rotasi, batubara dipindahkan secara bertahap menuju tabung pemanas dari inlet ke outlet. Di dalam tabung pemanas dipasang screw guides, yang mengontrol perpindahan batubara. Variable pitch guides yang dipasang di dalam tabung mencegah perpindahan batubara dalam tabung yang terlalu cepat. Batubara yang sudah kering dikumpulkan di bagian bawah ruangan. Kondensasi uap dikeringkan melalui pin yang ditempatkan di bagian bawah drum. Pada pengering jenis ini, koefisien perpindahan konveksi dari uap ke batubara sekitar $25 \mathrm{~W} / \mathrm{m}^{2} \mathrm{~K}$.

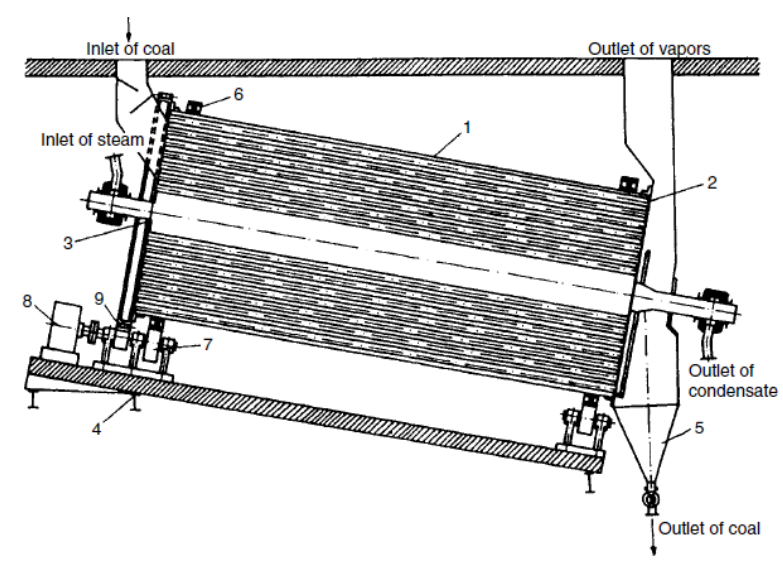

Gambar 3. Rotary Tube Dryer

Sedangkan pada pabrik briket batubara lignit, pengering ini dipanaskan oleh uap yang dikeluarkan dari mesin briket. Sisa minyak keluar dari aliran uapyang dikarbonisasi, membentuk endapan pada dinding tabung. Untuk menghilangkan kotoran dari tabung pengering, tabung ini dapat dicuci dengan sirkulasi trikloroetilen pada 70 hingga 80 0C selama sekitar 3 jam. Trikloroetilen bekas disuling untuk digunakan kembali. Membuat bentuk flight ' $\mathrm{Y}$ ' dalam rotary tube dryer 
merupakan pendekatan yang efisien untuk meningkatkan rasio pengisian material dan area pertukaran panas. Struktur yang dioptimalkan mampu mengurangi keausan material terhadap permukaan tabung, akibat kecepatan partikel maksimum yang rendah. Struktur yang dioptimalkan menghasilkan distribusi kecepatan partikel yang seragam dan koefisien perpindahan panas permukaan rata-rata yang tinggi dari tabung (Li et al., 2018).

\section{Pengaruh Nilai Kalor Batubara Terhadap Biaya Bahan Bakar Produksi}

Syahputera telah melakukan sebuah studi tentang analisa pengaruh perubahan nilai kalor batubara terhadap biaya bahan bakar produksi di PLTU Palabuhanratu dengan kapasitas 320 MW neto (Syahputera et al., 2018). Dalam penelitian ini menggunakan kalori batubara dengan rentang $4.200 \mathrm{kcal} / \mathrm{kg}$ sampai dengan $4.430 \mathrm{kcal} / \mathrm{kg}$. Pengujian dilakukan pada tiga tingkat beban yang berbeda yaitu $240 \mathrm{MW}$, $280 \mathrm{MW}$, dan 320 MW. Parameter kinerja efisiensi thermal pada PLTU dinyatakan dalam Net Plant Heat Rate (NPHR) dalam kcal/kWh. NPHR adalah banyaknya jumlah energi yang diperlukan suatu pembangkit untuk menghasilkan satu kWh listrik netto. Semakin kecil nilai NPHR suatu pembangkit, maka semakin tinggi efisiensi thermal pembangkit tersebut.

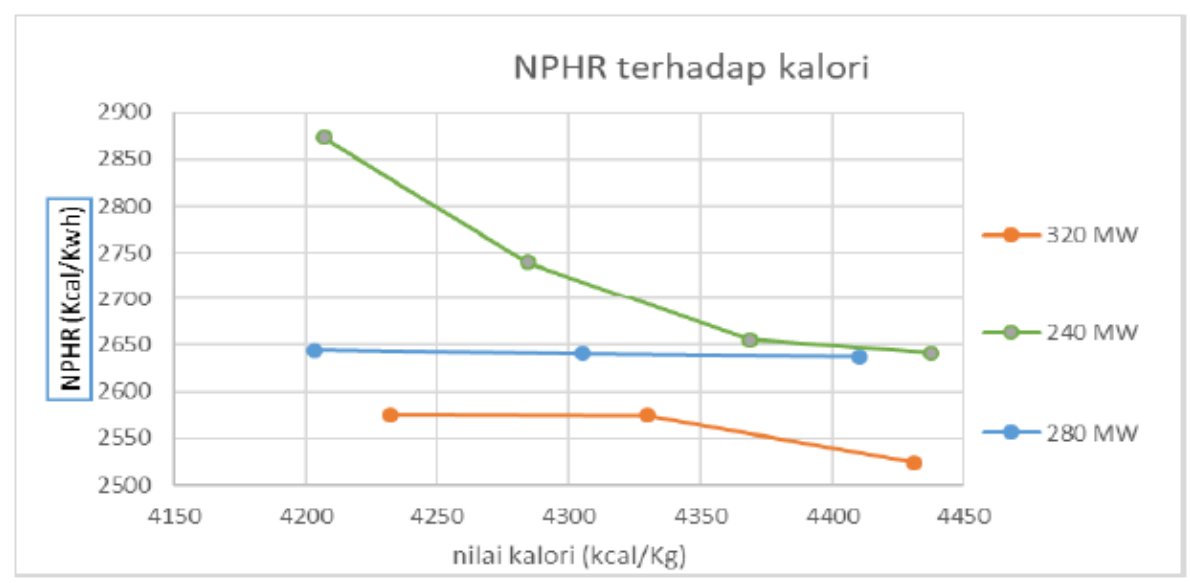

Gambar 4. Grafik NPHR terhadap Nilai Kalor Batubara (Syahputera et al., 2018)

Gambar 4 menunjukkan bahwa nilai Net Plant Heat Rate (NPHR) menurun seiring naiknya nilai kalori batubara. hal ini dikarenakan semakin tinggi nilai kalori batubara maka jumlah moisture dan ash pada batubara akan menurun, dengan menurunnya nilai moisture dan ash tersebut maka rugi rugi pembakaran dapat berkurang dan panas yang dihasikan batubara pada proses pembakaran dapat dimanfaatkan lebih maksimal, sehingga nilai heat rate dapat menurun. Pada beban tinggi panas yang dihasilkan bahan bakar akan diserap lebih optimum sehingga daya yang dihasilkan lebih besar dan rugi rugi yang terjadi relatif lebih rendah, sehingga kebutuhan nilai panas untuk menghasilkan energi listrik berkurang.

Dengan mengkalikan nilai NPHR, produksi MW net, dan harga energi primer akan diperoleh biaya bahan bakar produksi dala satuan Rp/kWh. Data Harga Patokan Batubara (HPB) dapat dilihat pada tabel 3 . 
Tabel 3.

Data Harga Patokan Batubara

\begin{tabular}{|c|c|c|c|}
\hline Merek Dagang & $\begin{array}{c}\text { Nilai Kalori GAR } \\
(\mathrm{kCal} / \mathrm{kg})\end{array}$ & $\begin{array}{c}\text { HPB Marker } \\
(\mathrm{USD} / \text { ton })\end{array}$ & $\begin{array}{c}\text { Harga Energi } \\
(\mathrm{Cent} / \mathrm{kCal})\end{array}$ \\
\hline Gunung Bayan I & $7,000.00$ & 89.98 & 1.29 \\
\hline Prima Coal & $6,700.00$ & 89.76 & 1.34 \\
\hline Pinang 6150 & $6,200.00$ & 80.99 & 1.31 \\
\hline Inominco & $5,700.00$ & 68.52 & 1.20 \\
\hline Melawan Coal & $5,400.00$ & 65.90 & 1.22 \\
\hline Envirocoal & $5,000.00$ & 61.64 & 1.23 \\
\hline Jorong J-I & $4,400.00$ & 49.65 & 1.13 \\
\hline Ecocoal & $4,200.00$ & 45.38 & 1.08 \\
\hline
\end{tabular}

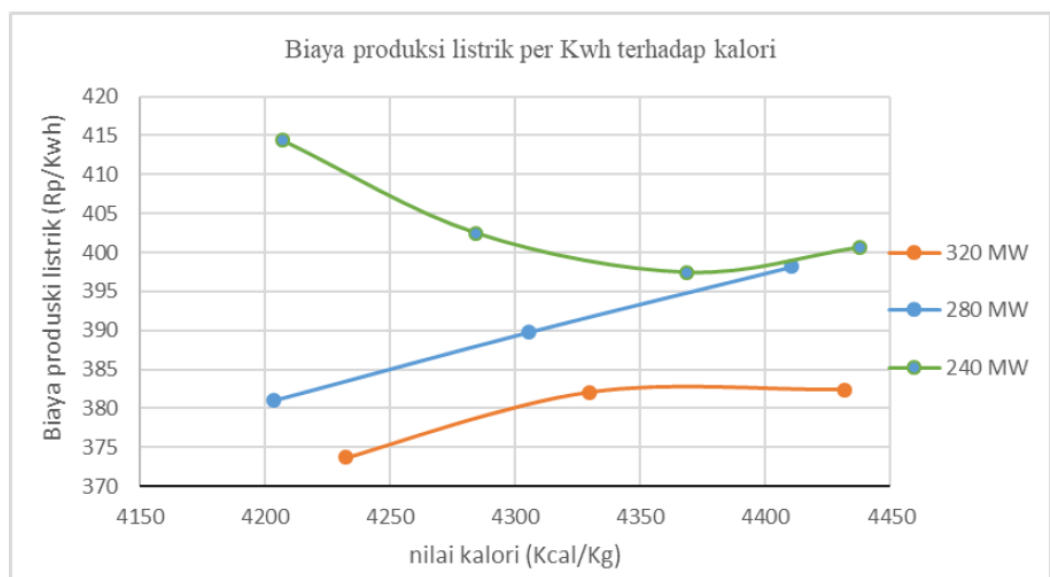

Gambar 5. Grafik Biaya Bahan Bakar Produksi Terhadap Nilai Kalor Batubara (Syahputera et al., 2018)

Gambar 5 menunjukkan pada beban 240 MW biaya produksi listrik pada pemakain batubara dengan nilai kalor $4.206 \mathrm{kcal} / \mathrm{kg}$ tinggi, hal ini disebabkan oleh NPHR yang tinggi, seiring dengan naiknya nilai kalor NPHR pun turun, tetapi tidak dengan biaya produksi listrik yang memiliki nilai optimum pada nilai kalori sekitar $4.300 \mathrm{kcal} / \mathrm{kg}$. Hal ini disebabkan karena pada titik tersebut adalah titik paling ideal antara NPHR dengan harga bahan batubara, karena walaupun NPHR menurun seiring naiknya nilai kalori yang dipakai tetapi harga batubara pun akan semakin mahal pada kalori yang lebih tinggi. Pada beban 280 MW dan 320 MW dapat dilihat biaya produksi listrik terbaik berada pada pemakaian batubara dengan nilai kalor rendah, hal ini menunjukan bahwa penurunan NPHR seiring naiknya nilai kalori batubara tidak sebanding dengan kenaikan harga batubara dengan kalori yang lebih tinggi. Pada beban 240 MW biaya produksi listrik terendah didapat pada pemakaian batubara berkalori 4.368 kcal/kg dengan biaya produksi listrik sebesar Rp 397,47 /KWh. Sedangkan pada beban 280MW dan 320 MW biaya produksi listrik terendah didapat pada pemakaian batubara kalori rendah yaitu $4.203 \mathrm{kcal} / \mathrm{kg}$ dan $4.232 \mathrm{kcal} / \mathrm{kg}$ dengan biaya bahan bakar produksi listrik Rp 381,02 per kWh dan Rp 373,67 per kWh. 


\section{Kesimpulan}

Sebagai salah satu upaya untuk memanfaatkan batubara nilai kalori rendah yang mempunyai harga energi yang relatif lebih murah, maka dapat dilakukan alternatif pemanfaatan batubara tersebut dengan metode coal blending, coal switching, ataupun coal drying pada PLTU. Coal blending merupakan cara terbaik untuk mengatasi masalah ketersediaan batubara dan ketergantungan terhadap satu sumber pemasok batubara untuk PLTU di Indonesia. Dengan mengganti batubara menjadi kalori yang lebih rendah memang akan menaikkan jumlah konsumsi batu bara dan menurunkan efisiensi pembangkit, namun karena harganya lebih murah, maka masih didapat penghematan secara finansial. Coal drying dapat menjadi salah satu alternatif untuk memperbaiki kualitas batubara yang mempunyai kandungan moisture tinggi, sehingga batubara tersebut dapat digunakan untuk bahan bakar PLTU eksisting. Hal yang perlu diperhatikan adalah evaluasi dari kinerja boiler setelah mengganti kualitas batubara yang lebih rendah, sejumlah uji bakar perlu dilakukan untuk mengetahui hasil pembakaran setiap batubara dengan karakteristik yang berbeda.

\section{Daftar Pustaka}

Amsya, R. M., \& Pelita, R. (2019). Model Coal Blending Beda Kualitas Untuk Memenuhi Permintaan Buyer. Jurnal Sains Dan Teknologi: Jurnal Keilmuan Dan Aplikasi Teknologi Industri, 19(1), 25. https://doi.org/10.36275/stsp.v19i1.130

Anang Nungky Ristyanto, Joko Windarto, S. H. (2012). SIMULASI PERHITUNGAN EFISIENSI SISTEM PEMBANGKIT LISTRIK TENAGA UAP (PLTU) REMBANG Anang Nungky Ristyanto 1), Joko Windarto 2), Susatyo Handoko 2) - PDF Free Download.pdf.

Aravind, R. A., Muthukumar, V., Kumaravel, S., \& Sivaprakash, E. (2020). Performance assessment of $2 \times 90$ tph (afbc) boiler and study of hp heater. Materials Today: Proceedings, xxxx. https://doi.org/10.1016/j.matpr.2020.05.389

ESDM. (2019). HANDBOOK OF ENERGY \& ECONOMIC STATISTICS OF INDONESIA 2019. Journal of Chemical Information and Modeling, 53(9), 1689-1699.

Li, X., Gao, L., Yun, D., Yang, L., Geng, W., \& Wu, J. (2018). A CFD modeling investigation for structure optimization of a rotary steam tube dryer. IOP Conference Series: Materials Science and Engineering, 397(1). https://doi.org/10.1088/1757-899X/397/1/012076

Mills, S. J. (2011). Global perspective on the use of low quality coals. In Iea Clean Coal Centre (Issue January).

Pikon', J., \& Mujumdar, A. (2006). Drying of Coal. Handbook of Industrial Drying, Third Edition, November 2006. https://doi.org/10.1201/9781420017618.ch43

PT. PLN (Persero). (2019). Electric Power Supply Business Plan (2019-2028). 2019-2028. http://gatrik.esdm.go.id/assets/uploads/download_index/files/5b16d-kepmen-esdm-no.-39-k-20-mem2019-tentang-pengesahan-ruptl-pt-pln-2019-2028.pdf

Sudirman, J. J. (2012). Peluang Aplikasi Teknologi Pengeringan Batubara dan Blending Batubara Di Indonesia Ditinjau Dari Segi Ekonomi dan Lingkungan. 8(September), 152-163.

Suprapto, S. (2009). Blending Batubara untuk pembangkit listrik - studi kasus PLTU Suralaya unit 1 - 4. In Jurnal teknologi mineral dan batubara: Vol. Vol. 5 (Issue 13, pp. 31-39).

Syahputera, I. M., Kamal, D. M., \& Ekayuliana, A. (2018). Analisis Pengaruh Nilai Kalori Batubara terhadap Konsumsi Bahan Bakar dan Biaya Produksi Listrik. Seminar Nasional Teknik Mesin, 474-483. http://semnas.mesin.pnj.ac.id/prosiding/2018_pdf/A054.pdf 
Vol. 1, No. 3, pp $100-110$

doi: $10.14710 /$ jebt.2021.10029

Tanetsakunvatana, V., \& Kuprianov, V. I. (2007). Experimental study on effects of operating conditions and fuel quality on thermal efficiency and emission performance of a 300-MW boiler unit firing Thai lignite. Fuel Processing Technology, 88(2), 199-206. https://doi.org/10.1016/j.fuproc.2006.04.005

Tillman, D. (2012). Solid Fuel Blending: principles, practices and problems. 337.

Tirumala Srinivas, G. (2017). Efficiency of a Coal Fired Boiler in a Typical Thermal Power Plant. American Journal of Mechanical and Industrial Engineering, 2(1), 32. https://doi.org/10.11648/j.ajmie.20170201.15

Zhu, Q. (2010). Coal sampling and analysis standards. IEA Clean Coal Centre, 2014, 123. https://www.usea.org/sites/default/files/042014_Coal sampling and analysis standards_ccc235.pdf 